\title{
Reliability Evaluation Based on a Fuzzy Expert System: Centrifugal Pump Application
}

\author{
Belhadef RACHID ${ }^{1}$, Ahmed HAFAIFA ${ }^{2}$, Nadji HADROUG ${ }^{2}$, Mohamed BOUMEHRAZ ${ }^{3}$ \\ ${ }^{1}$ Faculty of Science and Technology, University of Jijel, Algeria, \\ r.belhadef@univ-biskra.dz \\ ${ }^{2}$ Applied Automation and Industrial Diagnostics Laboratory, \\ Faculty of Science and Technology, University of Djelfa \\ 17000 DZ, Algeria, \\ Hafaifa.ahmed.dz@ieee.org, N_Hadrzoug@univ-djelfa.d \\ ${ }^{3}$ University of Biskra, Algeria, \\ medboumehraz@univ-biskra.dz
}

\begin{abstract}
In the development process of modern industrial systems, predictive reliability becomes very important in the design and exploitation of industrial facilities. This paper proposes the development of a new approach to the assessment of predictive reliability, applied to a centrifugal pump based on a fuzzy expert system to improve its performance under actual operating conditions. The obtained results clearly demonstrate how the reproduction of the main dynamic characteristics of the examined pump, using the proposed fuzzy model enables better performance regarding reliability.

Keywords: Predictive reliability, reliability analyses, fuzzy system, fuzzy modelling, fuzzy expert system, centrifugal pump, safety system, industrial process.
\end{abstract}

\section{Introduction}

Reliability analysis is essential for ensuring dependability in industrial systems. Today, the technological evolution of industrial equipment has led to significant progress in the areas of quality and dependability to meet the needs of the user, particularly in the process of quality improvement that impacts the predicted reliability. Indeed, reliability has become a key quality and decision support parameter because reliability covers multiple aspects, such as failure analysis systems.

Several studies have been conducted to assess as accurately as possible the predictive reliability [1, 2, 3, 4, 5 and 6]. Many persistent problems exist in the field of predictive reliability, such as population samples, rates of non-constant failures, lengthy and expensive trials, missing data and other technical and practical problems. This work proposes a fuzzy model describing the predictive reliability of a centrifugal pump. This method of evaluation and reliability analysis is based on the field of artificial intelligence, specifically fuzzy expert systems, and offers advantageous performance in the modelling of the predicted reliability of the process considered.

In this work, through the various tests using real data, we clearly demonstrate that the obtained results using the proposed fuzzy model reproduce the main reliability features in the examined pump, allowing for the best performance when used for calculations of the failure rates of each component of the examined centrifugal pump.

\section{Reliability in Industrial Systems}

The first task in the reliability analysis is to determine the reliability value to analyse for each component separately. Then, we determine the global reliability of the system; this task allows us to understand the properties and dependencies of the studied system. Reliability is defined in probability terms using probabilistic parameters, such as cumulative distribution functions, the failure rate, and the average uptime [7,8 and 9]. The cumulative distribution $F(t)$ is defined as the probability in a random interval that the random variable is not large at time $t$ :

$$
F(t)=\int_{-\infty}^{t} f(t) d t
$$

where $f(t)$ is the probability density of the random variable.

Therefore, the reliability function $R(t)$ is given by:

$$
R(t)=1-F(t)=\int_{t}^{\infty} f(t) d t
$$

By differentiating equation (2), we find: 


$$
\frac{-d R(t)}{d t}=f(t)
$$

The probability of failure in a definite time interval between $t_{1}$ and $t_{2}$ is expressed by the following reliability function:

$$
\int_{t_{1}}^{\infty} f(t) d t-\int_{t_{2}}^{\infty} f(t) d t=R\left(t_{1}\right)-R\left(t_{2}\right)
$$

The failure rate $\lambda(t)$ is defined as the ratio between the failure probability in the time interval between $t_{1}$ and $t_{2}$ and the product of the failure probability in $t_{1}$ with the length of this interval.

$$
\lambda(t)=\frac{R\left(t_{1}\right)-R\left(t_{2}\right)}{\left(t_{1}-t_{2}\right) R\left(t_{1}\right)}
$$

which in an alternative form is given by:

$$
\lambda(t)=\frac{R(t)-R(t+\Delta t)}{\Delta t R(t)}
$$

For the reliability evaluation in most industrial systems, the instantaneous rate of risk $h(t)$ is used, which is defined as the limit of the failure rate when the time interval approaches zero.

$$
\begin{aligned}
h(t) & =\lim _{\Delta t \rightarrow 0}\left[\frac{R(t)-R(t+\Delta t)}{\Delta t R(t)}\right]= \\
& =\frac{-1}{R(t)}\left[\frac{d R(t)}{d t}\right]= \\
& =\frac{1}{R(t)}\left[\frac{-d R(t)}{d t}\right]
\end{aligned}
$$

When equation (2) is replaced in (6), we find:

$$
h(t)=\frac{f(t)}{R(t)}
$$

The instantaneous rate of risk is given by:

$$
h(t)=\frac{-1}{R(t)}\left[\frac{d R(t)}{d t}\right] \Rightarrow \frac{d R(t)}{d t}=-h(t) d t
$$

By integrating both sides of equation (9), we find:

$$
\begin{aligned}
& \begin{aligned}
\int_{0}^{t} \frac{d R(t)}{d t} & =-\int_{0}^{t} h(t) d t \Rightarrow \ln R(t)-\ln R(0) \\
& =-\int_{0}^{t} h(t) d t
\end{aligned} \\
& R(t)=e^{\left(-\int_{0}^{t} h(t) d t\right)}
\end{aligned}
$$

Equation (11) is the general expression of the reliability function. If $h(t)$ is considered to be constant, the reliability function becomes:

$$
R(t)=e^{-\lambda t}
$$

In this case, the calculation of the average time of failure (MTTF) is given by:

$$
\text { MTTF }=\int_{0}^{\infty} t f(t) d t=\int_{0}^{\infty} t\left[-\frac{d R(t)}{d t}\right] d t
$$

By integration, we obtain the expression:

$$
M T T F=\int_{0}^{\infty} R(t) d t
$$

The average uptime (Mean Time Between Failures, MTBF) for repairable systems, which is the case of our application, in which elements are replaced immediately after failure, is determined by the following equation:

$$
M T B F=\frac{T(t)}{r}
$$

where $T(t)$ is the total operating time, and $r$ is the number of failures.

The mean time between failures (MTBF) can be calculated by other means:

$$
\begin{aligned}
& R(t)=e^{-\lambda t}=e^{-\frac{t}{\theta}}=e^{-\frac{t}{M T B F}} \\
& \lambda=\frac{1}{M T B F}
\end{aligned}
$$

where $\theta=\frac{\sum_{i=1}^{n} t_{i}}{n}$ is the average life duration, $t_{i}$ is the time to failure of the ith component in the population and $n$ is the total number of components in the population of system components.

Several laws and approaches are described in the literature for several industrial applications $[10$, $11,12,13,14$ and 15]. In this work, we used the exponential, Weibull and normal distributions to improve the proposed fuzzy expert system in this study. The exponential law is used to describe the period during which the failure rate of the equipment is assumed to be constant and is defined by a single parameter, the failure rate $\lambda$, which is characterised by reliability, and the Weibull distribution is often used in describing mechanical equipment, as it characterises the behaviour of a system with three phases of life according to the value of $\beta$ [16 and 17]. The normal distribution is widespread among the laws of probability as it applies to many phenomena. The normal distribution, as characterised by reliability, is defined by the mean $\mu$ and $\sigma$ standard deviation. To summarise the collected data on our application for each 
component, we used three types of distributions in the proposed fuzzy expert system in this work (Weibull, exponential and normal distributions), with the aim of developing a knowledge base from a system analysis throughout the lifetime of the system being examined, i.e., from its commissioning to its disintegration.

\subsection{Reliability fuzzy expert system}

Fuzzy logic was introduced in expert systems in several disciplines and can be integrated in different aspects, depending on the field of application and the complexity of the problem $[18,19,20,21,22]$. In the area of reliability prediction, fuzzy logic is a complicated approach, but offers major advantages regarding reliability assessment. Due to the lack of precision of the operating data in industrial equipment provided to the user who studied reliability assessment problems using expert systems, the fuzzy expert system used arranged mechanisms to deal with uncertain information $[23,24,25,26,27,28]$. In this work, the views of several experts can be reconciled within a model of the systems based on fuzzy rules by using comparison techniques to provide reliable decisions. In the case of data processing for a reliability study, the model allows the integration and processing of both the approximate nature of human knowledge, using defined categories such as good reliability, very good reliability limits, or little reliability, and intermediate situations between true and false, and it allows the introduction of a gradual transition from one to another. This allows to components not completely belong to either a set or the other, or partially in each belong.

For a countable set $X$ not of reliability, a fuzzy subset $A$ of $X$ is characterised by its membership function $\mu_{A}$, i.e.:

$$
\begin{aligned}
\mu_{A}: X & \rightarrow[0,1] \\
x & \rightarrow \mu_{A}(x)
\end{aligned}
$$

where $\mu_{A}(x)$ is the degree of belonging to the fuzzy set (membership function degree). In this work, the Gaussian membership function is used to represent the linguistic variables of the reliability is given as follows:

$$
\mu_{A i}(x)=\exp \left(-\frac{\left(c_{i}-x\right)^{2}}{2 \sigma_{i}^{2}}\right)
$$

where $c_{i}$ is the centre of the $i^{\text {th }}$ fuzzy set $A^{i}$ and $\sigma_{i}$ is its width.
The Gaussian membership is used to model the imprecise and unknown knowledge about the reliability data using the function shown in Figure 1.

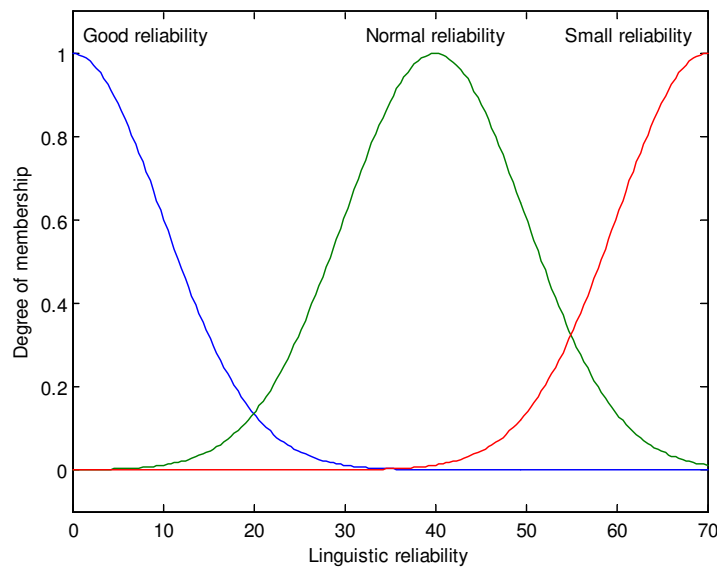

Figure 1. Gaussian membership

To draw conclusions about the reliability of the study system, a fuzzy algorithm is used to model the reliability, this algorithm is based on a collection of rules $R_{i}$ of the form If-Then:

$$
R_{i} \text { : If } x \text { is (condition) } A_{i} \text { Then } y_{i}=f(x)
$$

The activation degree of a rule is calculated using appropriate T-norm or T-conorm complementation operator, to collect the used rules, is given by the flowing equation:

$$
\begin{aligned}
& \omega^{i}=\mu_{A_{1}^{i}}\left(x_{1}\right) \vee \mu_{A_{2}^{i}}\left(x_{2}\right) \wedge\left(1-\mu_{A_{3}^{i}}\left(x_{3}\right)\right) \\
& R_{i}: \text { If } x_{1} \text { is } A_{1}^{i} \text { or } x_{2} \text { is } A_{2}^{i} \text { and } \ldots \\
& \text { and } x_{p} \text { is } A_{p}^{i} \text { Then } y \text { is } f_{i} \\
& \omega^{i}=\mu_{A_{1}^{i}}\left(x_{1}\right) \wedge \mu_{A_{2}^{i}}\left(x_{2}\right) \wedge \ldots \wedge \mu_{A_{p}^{i}}\left(x_{p}\right)
\end{aligned}
$$

Reliability composition max-min is defined by:

$$
\mu_{f}(y)=\max _{x} \min _{x, y}\left(\mu_{A}(x), \mu_{R}(x, y)\right)
$$

Using fuzzy mean defuzzification given by the flowing equation:

$$
y=\frac{\sum_{i=1}^{k} \omega^{i} \bar{y}^{i}}{\sum_{i=1}^{k} \omega^{i}}
$$

where $\omega$ is the activation degree of the $i^{\text {th }}$ rule, for the T-norm $\omega$ is given by the flowing equation:

$$
\omega^{i}=\prod_{i=1}^{p} \mu_{A_{i}^{p}}\left(x_{i}\right)
$$

The fuzzy reliability function $R_{F u z z y}$ is based on the failure rate analyses $\lambda(t)$ given by the 
equation (5) defined in the time interval $t_{1}$ and $t_{2}$ for any failure threshold, is given by the flowing equation:

$$
R_{\text {Fuzzy }}(t)=1-F(t)= \begin{cases}1 & \text { if } \mu_{A i}(x) \geq \lambda \\ 0 & \text { if } \mu_{A i}(x)<\lambda\end{cases}
$$

Using the reliability distribution given by the equation (2) in the developed fuzzy expert system, the fuzzy reliability function $R_{F u z z}(x)$ can be expressed by:

$$
R_{\text {Fuzzy }}(x)=\int_{-\infty}^{+\infty} f(x) \mu(x) d x
$$

The Gaussian membership function to determine the failure probability $F(x)$ defined in the time interval $t_{1}$ and $t_{2}$ is given as follows:

$$
\begin{aligned}
& F(x)=1-R_{\text {Fuzzy }}(x)=1-\int_{-\infty}^{+\infty} f(x) \mu(x) d x \\
& =1-\int_{-\infty}^{+\infty} f(x)\left[\min \left(\max \left(\exp \left(-\frac{\left(c_{i}-x\right)^{2}}{2 \sigma_{i}^{2}}\right), 0\right), 1\right)\right] d x \\
& =1-\left[\int_{t_{1}}^{t_{2}} \exp \left(-\frac{\left(c_{i}-x\right)^{2}}{2 \sigma_{i}^{2}}\right) f(x) d x+\int_{t_{2}}^{+\infty} f(x) d x\right]
\end{aligned}
$$

Equation (26) is used in the fuzzy expert system to assess the predictive reliability, as applied to the centrifugal pump considered in this work.

\section{Industrial Application}

To validate the developed approach in this work, we considered a centrifugal pump, shown in Figure 2, with axial flow and a single stage. To evaluate the predictive reliability of the model for the pump under study, the model must take into account all the main components [29, 30, 31, and 32]; the evaluation is based on the failure rate analyses, which is the basis for calculating the predicted reliability.

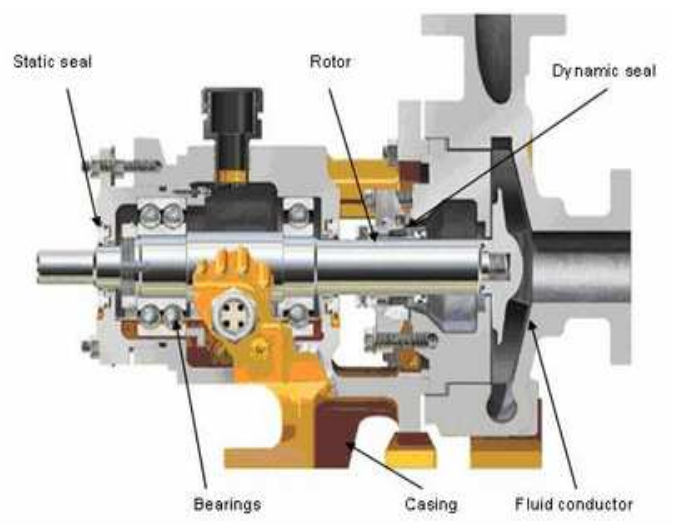

Figure 2. The centrifugal pump of Blackmer type under study
The first step is to calculate failure rate for the six main components (shaft (rotor), static seals, dynamic seals, fluid driver, bearings and casing), using actual operating data in the plant. The proposed approach in this work is shown in the diagram of Figure 3, based on the use of the developed fuzzy expert system structure.

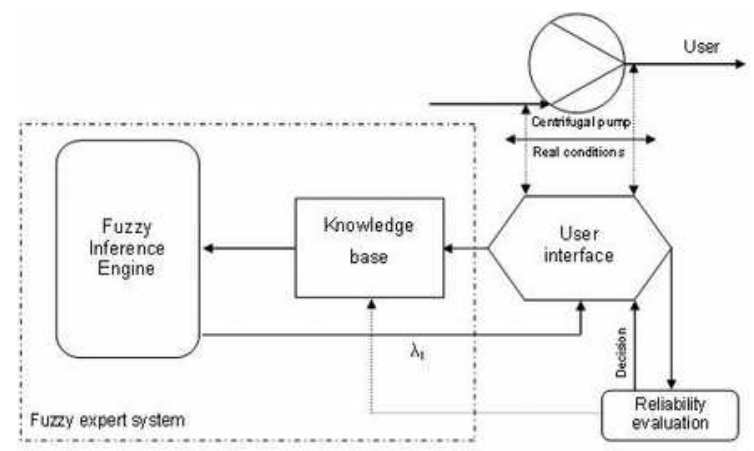

Figure 3. Proposed fuzzy expert system structure

\subsection{Application results}

Based on real operating data, the expert system provided several results as the parameters of the laws of the distribution of the failure rate and the predicted reliability, in addition to the average uptime and the instantaneous rate of failure for each component for the examined centrifugal pump. The predictive reliability evaluations of static seals, using the developed expert system, confirm that the form of failure rate of this component is an exponential distribution form (shown in Figure 4). By using the fuzzy expert system for dynamic seals, we found that the reliability of this component follows the shape of a Weibull distribution, as shown in Figure 5.

The results indicate that the static seals are highly reliable components; the probability of failure for this component does not exceed the limit of $10 \%$ after 5 years of operation, which implies that the stationary elements are the most reliable and that the choice of material plays an important role in its reliability system. Additionally, the results confirm that the failure rate for the dynamic seals is a Weibull distribution, with a high hill that explains the rapid decline in the reliability of the dynamic seals, which is characteristic of the low reliability of the dynamic elements caused by fatigue of these components; in fact, the reliability is equal to zero after one year of operation. Figures 6 and 7 show the results of the application of the fuzzy expert system for both the rotor and the bearings of the examined pump. 


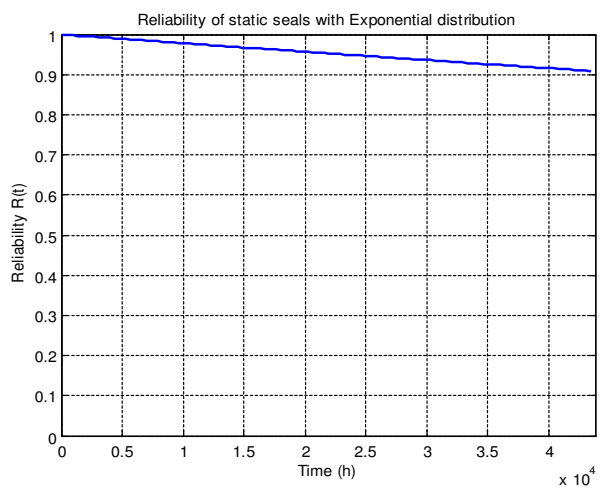

Figure 4. Reliability of the static seals

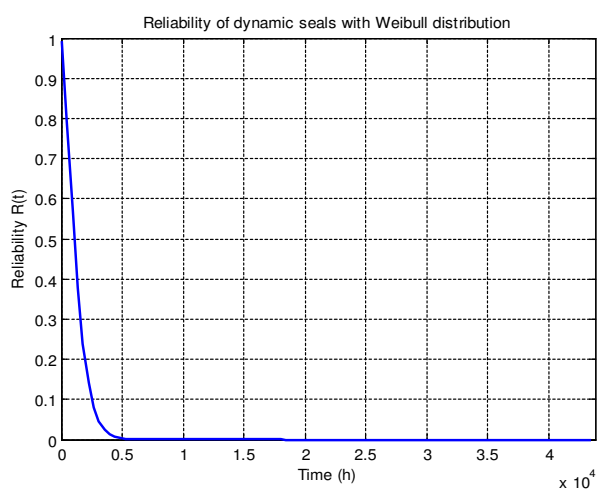

Figure 5. Reliability of the dynamic seals

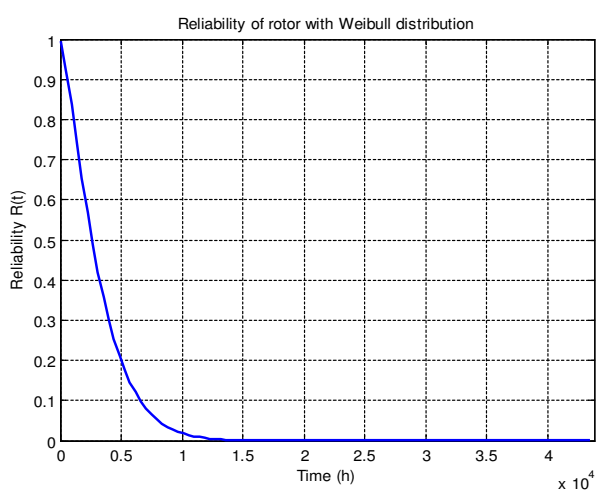

Figure 6. Reliability of the rotor

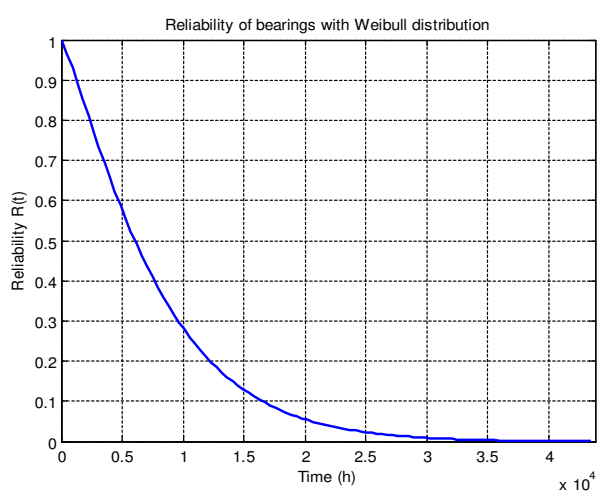

Figure 7. Reliability of the bearings

From figure 6, we conclude that the rotor is the most reliable dynamic component of the centrifugal pump; this reliability returned to the strength of the material of construction. With a very high failure rate, the bearings are the least reliable components in the centrifugal pump, for which the average temple proper functioning of the bearings does not exceed 200 days in general. The prediction reliability of the fluid driver follows an exponential distribution, as shown in Figure 8. Figure 9 show the results of the application of the fuzzy expert system for the casing of the studied pump.

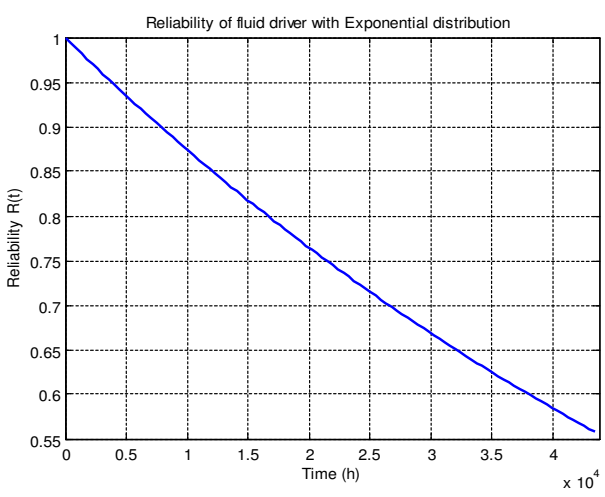

Figure 8. Reliability of the fluid driver

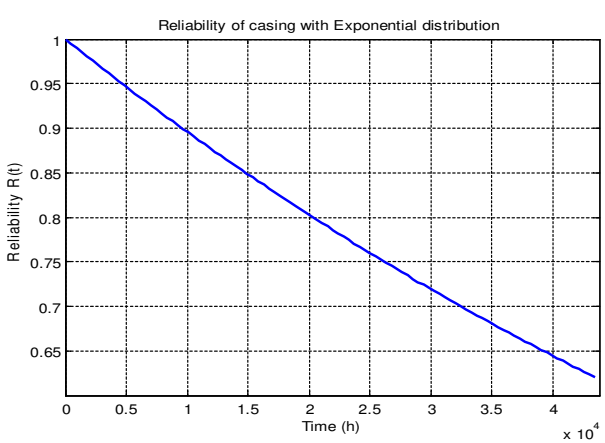

Figure 9. Reliability of the casing

The fluid driver is the element responsible for the axial fluid line in the centrifugal pump, which must exhibit simplicity and hardness to achieve a very small failure rate and high reliability convergence, accounting for $80 \%$ of the temple of the centrifugal pump operation. The prediction results clearly indicated a nearly perfect reliability of the casing, with $99 \%$ reliability during the five years of operation, i.e., the envelope is extremely reliable and its value does not affect the overall reliability centrifugal pump.

Finally, the prediction results of the global reliability using the fuzzy expert system for the examined centrifugal pump is shown in Figures $10,11,12,13$ and 14 .

The obtained results given by this reliability evaluation of the investigated centrifugal pump based on the fuzzy expert system confirm that 


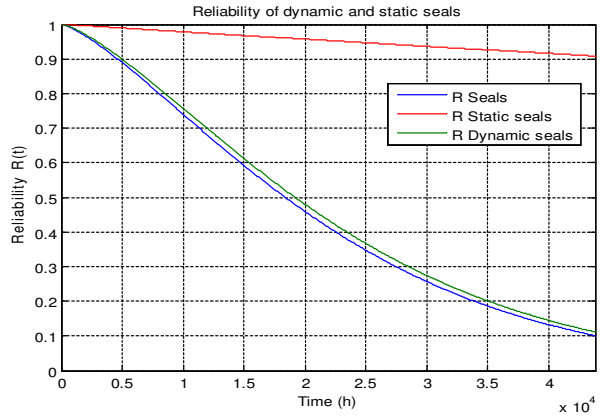

Figure 10. Reliability of the static and dynamic seals of the examined centrifugal pump

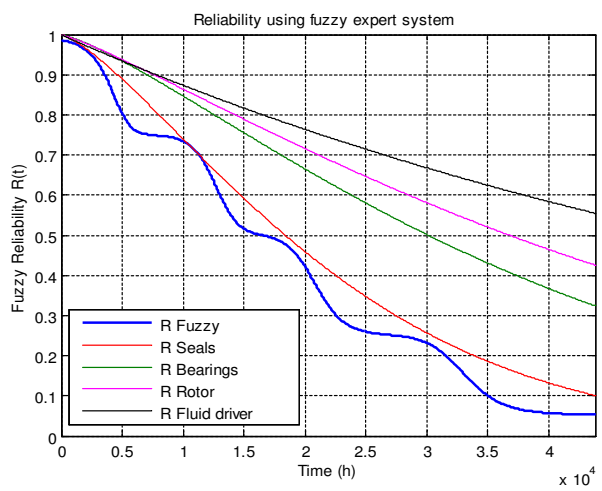

Figure 11. Fuzzy reliability of the components of the examined centrifugal pump

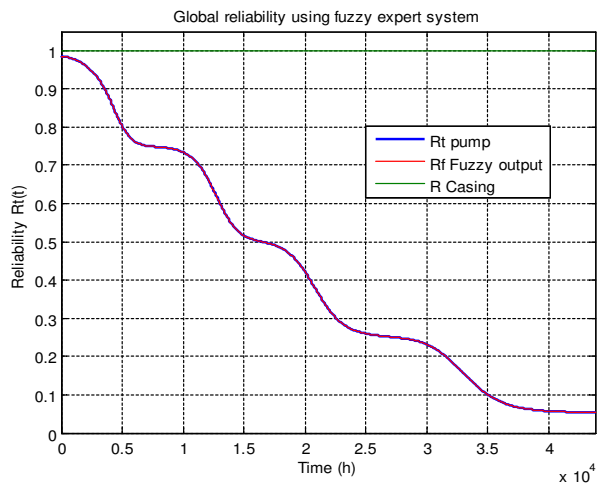

Figure 12. Global reliability using the fuzzy expert system of the examined centrifugal pump

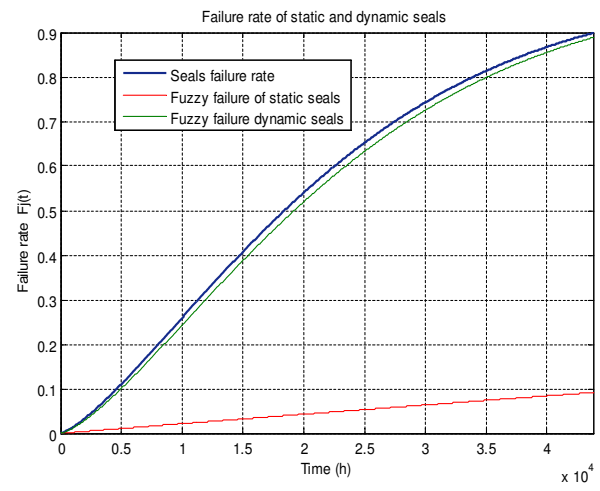

Figure 13. Failure rate of the static and dynamic seals of the examined centrifugal pump

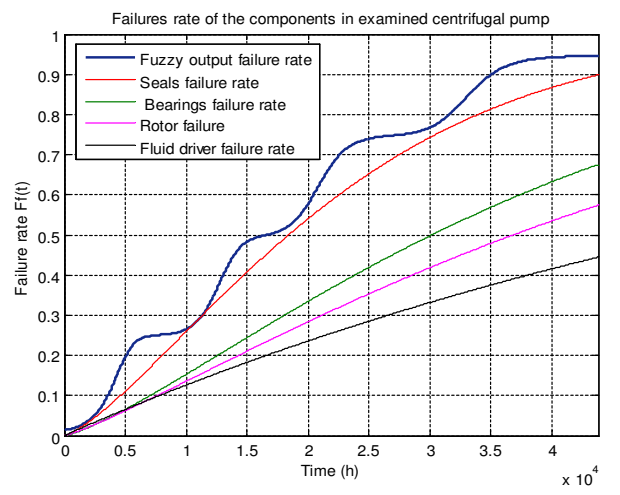

Figure 14. Failure rate of the components of the examined centrifugal pump

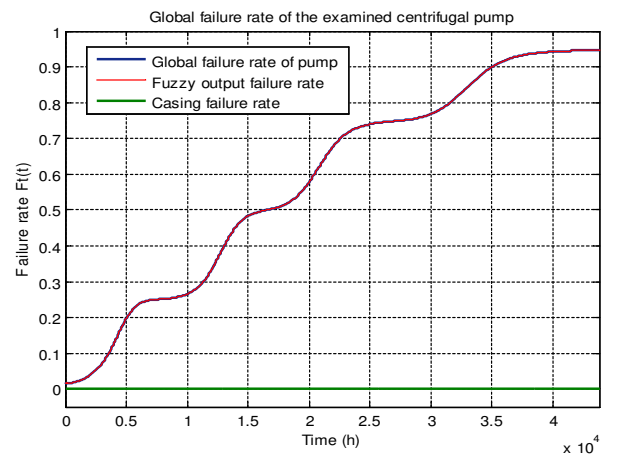

Figure 15. Global failure rate of the examined centrifugal pump

the dynamic seals are the least reliable elements, which exhibit the highest failure rate that causes the joint reliability to reduce to $50 \%$ in just two years. Additionally, the reliability of the bearings has a significant role in determining the overall reliability of the pump, as its reliability declines to $50 \%$ in 3.4 years, while the fluid driver kept $70 \%$ of its initial reliability. The casing reliability remains at its initial value $(100 \%)$. With the exploitation conditions of the examined pump, we concluded that the centrifugal pump arrives at total failure in 4 years, which requires maintenance to improve the overall reliability of the pump, and it is proposed that the replacement of the dynamic seals and bearings should be performed every two years to avoid failure caused by fatigue in the elements of the centrifugal pump.

\section{Conclusion}

The use of predictive reliability assessment in industrial equipment is essential to design systems that are more efficient. In this work, we have developed an evaluation of the reliability prediction method for industrial 
systems, taking a centrifugal pump as an example of the application of the method to assess as accurately as possible the predicted reliability of this system. A fuzzy model based on a fuzzy expert system describing the linguistically predicted reliability was proposed in this paper. This method of reliability evaluation and analysis, which is based on artificial intelligence techniques, provided encouraging results, taking into account the relationships between different components in a single system while emphasising the degree of importance of the component in the overall system structure. Through the different tests performed in the field, the results based on fuzzy rules clearly reproduced the main reliability features of the examined pump. The proposed approach uses fuzzy matching techniques to provide good decisions for assessing the reliability using fuzzy reasoning, which is used to integrate the knowledge of human experts of the equipment on the ground.

\section{REFERENCES}

1. BELHADEF, R., A. HAFAIFA, M. BOUMEHRAZ, Vibrations Detection in Industrial Pumps based on Spectral Analysis to Increase Their Efficiency, Management Systems in Production Engineering, 2016, vol. 1(21), pp. 55-61.

2. CHATTERJEE, S., S. NIGAM J. B. SINGH, L. N. UPADHYAYA, Application of Fuzzy Time Series in Prediction of Time between Failures \& Faults in Software Reliability Assessment, Fuzzy Information and Engineering, vol. 3(3), 2011, pp. 293-309.

3. COOLEN, F. P. A., P. COOLENSCHRIJNER, K. J. YAN, Nonparametric Predictive Inference in Reliability, Reliability Engineering \& System Safety, vol. 78(2), 2002, pp. 185-193.

4. HALIMI, D., A. HAFAIFA, E. BOUALI, Maintenance Actions Planning in Industrial Centrifugal Compressor based on Failure Analysis, Maintenance and Reliability, vol. 16(1), 2014, pp. 17-21.

5. SYOMIN, D., A. ROGOVYI, Features of a Working Process and Characteristics of Irrotational Centrifugal Pumps, Procedia Engineering, vol. 39, 2012, pp. 231-237.
6. LI, F., G. ZHENG, Z. TIAN, Optimal Operation Strategy of the Hybrid Heating System Composed of Centrifugal Heat Pumps and Gas Boilers, Energy and Buildings, vol. 58, 2013, pp. 27-36.

7. GUO, S.-X., Z.-Z. LÜ, Procedure for Computing the Possibility and Fuzzy Probability of Failure of Structures, Applied Mathematics and Mechanics, vol. 24(3), 2003, pp. 338-343.

8. HAFAIFA, A., A. Z. DJEDDI, A. DAOUDI, Fault Detection and Isolation in Industrial Control Valve based on Artificial Neural Networks Diagnosis, J. of Control Engineering and Applied Informatics, vol. 15(3), 2013, pp. 61-69.

9. HAFAIFA, A., R. BELHADEF, M. GUEMANA, Reliability Model Exploitation in Industrial System Maintainability using Expert System Evaluation, Procs. of the 4th International Conference on Integrity, Reliability and Failure IRF201323-27 June 2013, Funchal, Madeira, Portugal. pp. 387-388.

10. HARI PRASAD M., A. RAMI REDDY GSRIVIDYA., A. K. VERMA, Reliability Estimation of Passive Systems using Fuzzy Fault Tree Approach. Intl. Journal of System Assurance Engineering and Management, vol. 3(3), 2012, pp. 237-245.

11. WU, H.-C., Bayesian System Reliability Assessment under Fuzzy Environments, Reliability Engineering \& System Safety, vol. 83(3), 2004, pp. 277-286.

12. WU, H.-C., Fuzzy Bayesian Estimation on Lifetime Data, Computational Statistics, vol. 19(4), 2004, pp. 613-633.

13. ČERNETIČ, J., M. ČUDINA, Estimating Uncertainty of Measurements for Cavitation Detection in a Centrifugal Pump, Measurement, vol. 44(7), 2011, pp. 1293-1299.

14. JOE ASKEW, Centrifugal Pumps Avoiding Cavitation, World Pumps, vol. 2011(7-8), 2011, pp. 34-36, 38-39.

15. LI, B., M. ZHU, K. XU, A Practical Engineering Method for Fuzzy Reliability Analysis of Mechanical Structures, Reliability Eng. \& System Safety, vol. 67(3), 2000, pp. 311-315. 
16. MARCELLO BRAGLIA, GIONATA CARMIGNANI, MARCO FROSOLINI, FRANCESCO ZAMMORI, Data Classification and MTBF Prediction with a Multivariate Analysis Approach, Reliability Engineering \& System Safety, vol. 97(1), 2012, pp. 27-35.

17. MAURIZIO

BEVILACQUA, MARCELLO BRAGLIA, ROBERTO MONTANARI, The Classification and Regression Tree Approach to Pump Failure Rate Analysis, Reliability Engineering \& System Safety, vol. 79(1), 2003, pp. 59-67.

18. MYRTO KONSTANDINIDOU, ZOE NIVOLIANITOU, CHRIS KIRANOUDIS, NIKOLAOS MARKATOS, A Fuzzy Modeling Application of CREAM Methodology for Human Reliability Analysis, Reliability Eng. \& System Safety, vol. 91(6), 2006, pp. 706-716.

19. OLGIERD HRYNIEWICZ, An Evaluation of the Reliability of Complex Systems using Shadowed Sets and Fuzzy Lifetime Data, International Journal of Automation and Computing, vol. 3(2), 2006, pp. 145-150.

20. OM PRAKASH YADAV, NANUA SINGH, RATNA BABU CHINNAM, PARVEEN S. GOEL, A fuzzy logic based approach to reliability improvement estimation during product development . Reliability Engineering \& System Safety, vol. 80(1), April 2003, Pages 63-74.

21. PUNIT SINGH, FRANZ NESTMANN, An optimization routine on a prediction and selection model for the turbine operation of centrifugal pumps, Experimental Thermal and Fluid Science, vol. 34(2), 2010, pp. 152-164.

22. QIMI JIANG, CHUN-HSIEN CHEN, A numerical algorithm of fuzzy reliability, Reliability Engineering \& System Safety, vol. 80(3), 2003, pp. 299-307.

23. RAJIV KUMAR SHARMA, DINESH KUMAR, PRADEEP KUMAR, Modeling system behavior for risk and reliability analysis using KBARM, Quality and Reliability Engineering International, vol. 23(8), 2007, pp. 973-998.

24. RAMIN GHOLIZADEH, ALIAKBAR MASTANI SHIRAZI, BAHRAM S. GILDEH, EYNOLLAH DEIRI, Fuzzy Bayesian system reliability assessment based on Pascal distribution, Structural and Multidisciplinary Optimization, vol. 40(1-6), 2010, pp. 467-475.

25. ROTSHTEIN A. P., Fuzzy-algorithmic reliability analysis of complex systems. Cybernetics and Systems Analysis, vol. 47(6), 2011, pp. 919-931.

26. ROTSHTEIN A. P., S. D. SHTOVBA, Modeling of the Human Operator Reliability with the Aid of the Sugeno Fuzzy Knowledge Base, Aut. and Remote Control, vol. 70(1), 2009, pp. 163-169.

27. ROTSHTEIN A. P., SHTOVBA S. D., Predicting the reliability of algorithmic processes with fuzzy input data, Cybernetics and Systems Analysis, vol. 34(4), 1998, pp. 545-552.

28. RYMA ACHOURI, OMEIMA NOUICER, HATEM MHIRI, PHILIPPE BOURNOT, Probable cause analysis of cracks observed on vertical centrifugal pump. Engineering Failure Analysis, Volume 29, April 2013, Pages 1-11.

29. SUBRATA CHAKRABORTY AND PALASH CHANDRA SAM, Probabilistic safety analysis of structures under hybrid uncertainty, International Journal for Numerical Methods in Engineering, vol. 70(4), 2007, pp. 405-422.

30. TRINATH SAHOO, Making centrifugal pumps more reliable, World Pumps, vol. 2009(513), 2009, pp. 32-36.

31. YU GE DONG, XIN ZHAO CHEN, HYUN DEOG CHO, JONG WAN KWON, Simulation of Fuzzy reliability indexes, KSME International Journal, vol. 17(4), 2003, pp. 492-500. 